\title{
El papel del Estado en la construcción de la memoria: el discurso de medios sobre el Museo de la Memoria de Buenos Aires
}

\author{
The Role of the State in the Construction of Memory: The Media
}

Discourse on the Museum of Memory in Buenos Aires

\author{
Mariana Pascual \\ Pontificia Universidad Católica de Chile \\ mariana.pascual@uc.cl
}

\begin{abstract}
Resumen
Este trabajo tiene como objetivo indagar acerca de la manera en la que cinco periódicos argentinos representaron la inauguración del Museo de la Memoria, sitio en honor de las miles de víctimas del genocidio cometido durante la última dictadura militar (1976-1983), a fin de determinar el papel del Estado en la construcción colectiva de la memoria. Se realizó un análisis léxico-gramatical de elementos valorativos y se identificaron las entidades evaluadas positiva y negativamente. Los resultados dan cuentan de un énfasis en la construcción de valores culturales relativos a la aceptación de la responsabilidad del Estado como elemento basal en la construcción de una memoria colectiva curativa. El evento analizado marcó un punto de inflexión en Argentina, constituyó el reconocimiento público de la necesidad de justicia para visualizar un futuro social en armonía.
\end{abstract}

Palabras clave: discurso de medios, memoria colectiva, dictadura argentina, Museo de Memoria

\begin{abstract}
This study examines the way in which five Argentinean newspapers represented the opening of the Museum of Memory, which honours the thousands of victims of the genocide committed during the last military dictatorship (1976-1983), in order to determine the role played by the State in the construction of collective memory. A lexico-grammatical analysis of evaluative elements was conducted and entities evaluated positively and negatively were also identified. Results point to a strong emphasis on cultural values related to acknowledging State responsibility as a fundamental requisite in the construction of a healing collective memory. The event under analysis represents a turning point in Argentina's memory, since it constituted a public acknowledgement of the fact that justice is required if a socially harmonious future is aspired.
\end{abstract}

Keywords: media discourse, collective memory, Argentinean dictatorship, Museum of Memory

Fecha de recepción: 7 de febrero de 2019 | Fecha de aceptación: 30 de julio de 2019 
El papel del Estado en la construcción de la memoria

\section{Introducción}

odas las sociedades atraviesan situaciones de crisis, de diferente magnitud. En un interesante análisis presentado en la obra sobre memoria editada ( por Wodak y Auer, Assman (18) afirma que luego de las catástrofes humanas, como guerras, atentados terroristas, o desastres naturales, existe una tendencia natural, de supervivencia mental, material y moral de alejarse de la escena del dolor y retornar a la situación de cotidianeidad tan rápidamente como sea posible. Esto implica la existencia de un período de silencio inmediatamente posterior a la crisis por parte de todos los involucrados, tanto "ganadores" como "vencedores", en tanto, según afirma la autora: "ambos lados tienen sus esqueletos en el ropero". Trascurrido un tiempo de luto, la sociedad como entidad colectiva debe comenzar a construir su memoria sobre el evento traumático atravesado. Este es un proceso dinámico, irregular, con distanciamientos y acercamientos a la historia reciente. En la construcción de la memoria entran en juego una enorme cantidad de elementos, que se vinculan no solamente con la experiencia sufrida sino también con los juegos de poder que se plantean luego de su finalización.

En la construcción de la memoria colectiva, que no necesariamente coincide con las memorias individuales, se van filtrando hechos atravesados, discursos pronunciados, y se generan de manera gradual evaluaciones de valores sociales que van conjugando un interjuego de posicionamientos ideológicos. Entre los aspectos que contribuyen a la construcción de la memoria colectiva encontramos un amplio rango de prácticas y simbolismos sociales, entre los cuales las prácticas discursivas juegan un papel preponderante. Sin embargo, también debemos considerar su interacción con otras, tales como el accionar de cortes y tribunales, la erección de monumentos, museos y exhibiciones, la producción de videos, documentales, películas, el establecimiento de días conmemorativos, la dedicación de oraciones, minutos de silencio, entre otros rituales culturales que construyen y consolidan diferentes versiones del pasado.

En este trabajo analizamos una situación de trauma de la historia reciente, la atravesada por Argentina durante la última dictadura militar (1976-1983), que ha sido reconocida como una de las luchas más cruentas de la historia del país. 
Nos focalizamos en una práctica discursiva en particular, la de los medios de prensa gráficos, en su representación discursiva de la inauguración del Museo de la Memoria de la Ciudad de Buenos Aires, en el predio de la Escuela de Mecánica de la Armada (conocido como ESMA), escenario de miles de detenciones ilegales, fusilamientos y violencia sin precedentes.

Nuestro objetivo es indagar acerca de la manera en la que cinco periódicos argentinos representaron la inauguración del Museo de la Memoria, a fin de determinar el papel del Estado en la construcción colectiva de la memoria. Los resultados pueden contribuir a una comprensión más acabada de la manera en la que se construye la memoria colectiva de los pasados traumáticos y del papel que juega el Estado en su configuración.

\section{Discurso y memoria}

Adherimos a la propuesta teórico-analítica del enfoque sociohistórico (DHA por sus siglas en inglés) propuesto por Wodak, que ha resultado de particular utilidad para el análisis de estudios de memoria, uno de los ejes transversales del discurso que analizamos. Los investigadores de esta temática coinciden en afirmar que algunas reacciones a sucesos de profundo impacto traumático son de carácter universal, y trascienden los límites culturales (Assman, en Wodak y Auer).

Las sociedades franquean diferentes etapas hasta lograr relativos equilibrios, que han sido denominados, con diversas connotaciones ideológicas, estados de pacificación, reconciliación, perdón, olvido, restitución, entre otros. Sin embargo, los estudios demuestran que, a diferencia de lo que sucede en el ámbito personal o familiar, los Estados son los entes responsables de los hechos sociales traumáticos. En consecuencia, para lograr estos relativos equilibrios sociales el Estado es el que tiene la responsabilidad de determinar quiénes son las víctimas y cuándo, dónde y con qué consecuencias se dieron los hechos. Así mismo, otros asuntos que deben competer a la sociedad en proceso de recuperación incluyen temáticas relacionadas con "la culpa, el trauma, la restitución y el futuro de las generaciones jóvenes" (Wodak y Auer 18). 
El papel del Estado en la construcción de la memoria

La temática ha producido numerosos estudios en respuesta a una variedad de factores, entre los que se destacan la conciencia social de la relevancia de los procesos de recuperación y reconciliación, la convicción de que no existen intentos exitosos de reprimir, eliminar u olvidar los hechos traumáticos del pasado, y la inevitabilidad de la influencia del pasado sobre el presente y sobre el futuro de las sociedades.

Las narrativas sobre el pasado reciente traumático conforman lo que Koselleck denomina una "consciencia histórica", compuesta por la polaridad que se establece entre "el espacio de la experiencia" y "el horizonte de la expectativa". Entre estos dos planos se encuentra el presente, constituido por multiplicidad de interpretaciones del pasado y mediando hacia el futuro. En sus reflexiones sobre memoria y justicia, Wodak y Auer argumentan que en el discurso de la historia reciente no se cuestionan fundamentalmente los hechos, sino las interpretaciones que se realizan de esos hechos. Es por eso que los aportes a la comprensión de esas interpretaciones son de gran relevancia.

Entre los aspectos que contribuyen a la construcción de la memoria colectiva las prácticas discursivas juegan un papel preponderante. Sin embargo, también debemos considerar su interacción con otras, tales como las acciones legales, la erección de monumentos, museos y exhibiciones, la producción audiovisual y de material didáctico para generaciones futuras, $y$ muchas otras producciones sociales que construyen y consolidan diferentes versiones del pasado.

En el contexto latinoamericano, se han desarrollado una variedad de análisis del discurso relacionados con la memoria colectiva y de los pasados traumáticos, abordados desde diversas perspectivas. Estos estudios incluyen los aportes compilados por Lavandera sobre los desaparecidos en la dictadura argentina; los de Zullo sobre la enseñanza de esta etapa de la historia reciente en las aulas; Achugar (Construccion de la memoria y What We Remember) y sus aportes a la comprensión de la dictadura militar en Uruguay desde el análisis del discurso de los militares; los estudios de Achugar, Fernández y Morales relativos al análisis de diversas prácticas culturales que se vinculan con la dictadura militar en Uruguay. Así mismo, cabe destacar los aportes de Oteíza (How Contemporary History) sobre la representación de la dictadura chilena en textos escolares, los estudios de Oteíza y Pinto (Agency), quienes analizaron la representación en el discurso didáctico 
tanto de Chile como de España; la investigación de Finocchio (Entradas educativas) sobre revistas educativas editadas desde finales del siglo XIX en Argentina; la de Dussel, Finocchio y Gojman (Haciendo memoria), quienes desarrollaron una interesante propuesta para la traspolación didáctica del Nunca Más, a fin de que fuese incorporado como material didáctico en ámbitos escolares; el trabajo de Vitale (Memoria y acontecimiento), quien estudió el empleo de múltiples estrategias argumentativas en periódicos de 1976 y su implicancia en el derrocamiento de Isabel Perón, entre otras valiosas contribuciones.

En un plano más general, debe destacarse un aporte particularmente meritorio a la manera en que las sociedades enfrentan sus pasados traumáticos. La clasificación de Assmann (Commemorative spaces, From Collective Violence), quien luego de observar el comportamiento de varias sociedades en situaciones postraumáticas distinguió cuatro tipos de prácticas: 1. olvido dialógico, 2. memoria para nunca olvidar, 3. memoria para olvidar y 4. memoria dialógica. En estudios previos, Pascual (Comming to terms, La violación de los derechos humanos, La asociación de recursos) demostró que Argentina se adhirió a un modelo de memoria para olvidar. Según afirma Assmann (From Collective Violence), éste se basa en la necesidad de romper el silencio para poder superar el dolor, la culpa y el odio por las atrocidades cometidas. Es la respuesta a los reclamos éticos y políticos que sufrieron numerosas sociedades posdictatoriales de Latinoamérica, la Sudáfrica postapartheid y muchas otras que practicaron crímenes inhumanos.

Cabe destacar que aquí el uso del término "olvidar" no es literal, sino que implica dimensionar la experiencia en un contexto histórico para poder avanzar hacia un futuro común. Así, su significado se asocia más a la noción de "superar" que a la de olvido, como una herramienta terapéutica que actúa a modo de "limpieza", para purgar los errores y así permitir la sanación. En el contexto de estas formas de acción colectiva se encuentran las declaraciones de justicia, usualmente establecidas por procesos de enjuiciamiento; y las demostraciones de remordimiento, o alguna forma de reconocimiento del mal cometido, de modo simbólico, normativo o instrumental. Todas estas acciones sociales son realizadas mediante prácticas discursivas. El vínculo entre memoria y discurso es ineludible. 
El papel del Estado en la construcción de la memoria

\section{La Argentina posdictatorial: construyendo gradualmente la memoria colectiva}

\subsection{El retorno a la democracia. La presidencia de Raúl Alfonsín (1983-1989)}

El retorno al sistema democrático y a la legalidad institucional constituye un hecho fundamental en la historia de la Argentina de finales del siglo xx. Luego de casi una década de crímenes que condujeron a la desaparición de 30.000 personas, y del desastre de la Guerra de las Malvinas, el 1 de julio de 1982 las acciones sociales se orientaron hacia el incuestionable retorno a un rumbo democrático (Benítez y Mónaco). En 1981, en medio de una profunda crisis interna, de inestabilidad económica, descrédito internacional y fuertes demandas internas, el gobierno militar levantó la prohibición política.

En un contexto social convulsionado se constituyó la Multipartidaria, agrupación que convocaba a partidos políticos, asociaciones empresariales y sindicatos, liderada por la Unión Cívica Radical y que impulsaba la participación ciudadana con miras a las inminentes elecciones democráticas. Se configuraron entonces los principales candidatos para liderar el proceso de la vuelta a la democracia. El peronismo impulsaba la candidatura del constitucionalista Ítalo Luder, a la vez que la Unión Cívica Radical proponía a Raúl Alfonsín, quien se distinguía "por sus fuertes críticas a los militares, su notable reclamo por los desaparecidos, y su compromiso de justicia para los responsables del horror" (Benítez y Mónaco 28). Alfonsín logró el $52 \%$ de los votos, y asumió su cargo de presidente el 10 de diciembre de 1983, dando por concluida una etapa trágica en la historia del país.

El mayor desafío que debió enfrentar fue el de diseñar reglas claras a fin de asegurar la continuidad y consolidar la validez democrática institucional, para lo cual debía lograr "que esas reglas y procedimientos fueran acatadas, al menos, por aquellos a quienes esas reglas determinan como participantes en el proceso" (O'Donnell 202). Al mismo tiempo, la sociedad exigía esclarecer los hechos y juzgar a los responsables del Golpe de Estado de 1976 por su sistemática violación de los derechos humanos. Respondiendo a las demandas sociales y en cumplimiento de sus promesas electorales, Alfonsín ordena el enjuiciamiento de siete jefes guerrilleros y de los miembros de las tres primeras juntas militares. Así mismo, constituye la 
Comisión Nacional sobre la Desaparición de las Personas (CONADEP) con el propósito de descubrir el destino de los miles de desaparecidos que había dejado como saldo el genocidio militar. La Comisión estaba constituida por un grupo de ciudadanos de reconocida trayectoria en el tema de los derechos civiles. Luego de diez meses de ardua labor, en septiembre de 1984, la comisión entregó el tan esperado informe, un documento de más de 50 mil páginas que hasta la fecha se considera el hecho judicial de mayor importancia en la historia de la defensa de los derechos humanos de la Argentina. Se publicó una sección resumida de los testimonios cuyo título, Nunca más, es símbolo de la ferviente lucha por la defensa de los derechos humanos.

El documento ha sido utilizado por comisiones designadas con propósitos similares en numerosos países y constituye un legado para la formación de valores democráticos, de defensa de la verdad y del ejercicio de la justicia de las nuevas generaciones. El informe Nunca Más se convirtió en Argentina en el relato canónico sobre las desapariciones (Crenzel).

Si bien Alfonsín cumplió con su promesa de enjuiciar a los militares responsables del genocidio, implementando los instrumentos legales para que la Cámara Federal en 1986 condenara a los más altos mandos militares, el clima social conflictivo no se disipó. En este intento de reconstruir el recorrido desde el retorno a la democracia, debemos hacer mención de la "teoría de los dos demonios", conjunto de creencias impulsadas durante esta etapa histórica en la que actores sociales de derecha, usualmente afines a los militares, apelaron a esta figura en un intento por explicar lo sucedido en el país en la década de los noventa. Así, un énfasis en la violencia perpetrada por organizaciones de izquierda como Montoneros, el Ejército Revolucionario del Pueblo (ERP) o las Fuerzas Armadas Peronistas (FAP) justificaría u ocasionaría la reacción de las fuerzas militares previas y durante la dictadura. Esta teoría da cuenta de las graves diferencias que reinaban en la sociedad de los ochenta, posteriores al retorno a la democracia.

En esta misma línea, y profundizando las diferencias, encontramos las muy controvertidas Leyes de Obediencia Debida y Punto Final, sancionadas por Alfonsín en 1987, que liberaban de responsabilidad a un importante número de jefes militares que participaron en la represión. Hasta la actualidad continúa un debate 
El papel del Estado en la construcción de la memoria

sostenido sobre el espíritu de la cuestionada justicia y los efectos que estas leyes tuvieron en la institucionalidad del país.

Si bien el gobierno de Alfonsín permanece en la historia como una etapa de tensión y de intentos muchas veces infructuosos por imponer un orden institucional y económico equilibrado, la grandeza de sus esfuerzos por proteger los valores democráticos es reconocida nacional e internacionalmente.

\subsection{La década menemista (1989-1999)}

Tras anticipados comicios, Carlos Saúl Menem tomó posesión de la presidencia argentina hasta diciembre de 1999, luego de que la reforma constitucional de 1994 le posibilitara la reelección en el cargo. Su toma de posesión fue histórica, ya que marcó el primer traspaso del mando de un presidente elegido democráticamente a otro en igualdad de condiciones desde 1928.

Su gobierno se basó primordialmente en su sumisión absoluta a las imposiciones de fuerzas internacionales, que exigían límites severos a la naturaleza y al tipo de políticas económicas y sociales. Menem, en su afán por escapar de la hiperinflación, adoptó fielmente las indicaciones del Consenso de Washington, y ciñó sus opciones políticas y económicas a los parámetros establecidos por este consenso con la convicción de que el éxito en la acción de su gobierno resultaría de la aceptación sin cuestionamientos de las exigencias de organismos internacionales. Los reclamos de las organizaciones de derechos humanos fueron silenciados e ignorados sistemáticamente durante toda una década. Esto generó reacciones de gran disconformidad por parte de numerosos organismos, que activamente comenzaron a rechazar las acciones del gobierno.

Esta profunda insatisfacción ante las acciones del gobierno se vio particularmente reflejada en las áreas de los derechos humanos y la construcción de la memoria. $\mathrm{Al}$ respecto, el gobierno de Carlos Menem tomó una serie de medidas que generaron un enorme rechazo por parte de amplios sectores de la sociedad argentina que continuaban luchando por la justicia y el reconocimiento de las atrocidades cometidas en época de dictadura. Un claro ejemplo del espíritu contrario a esta búsqueda de verdad y justicia fue el indulto que el entonces presidente de Argentina concedió entre 1989 y 1990 a civiles y militares que habían sido condenados por 
los crímenes cometidos. Si bien utilizó el fundamento de una supuesta "pacificación", las consecuencias de estos dispositivos legales no hicieron más que agravar el malestar social ante el pasado que se construía en el recuerdo como conflictivo, fuente de tensiones no resueltas, heridas abiertas y reclamos ignorados.

En este ámbito, la política menemista fue sumamente ofensiva para la mayoría de los argentinos. Se empeñó en implementar acciones inconsultas, aleatorias y altamente impopulares. Tal es así que a inicios de 1998 anunció la demolición del edificio de la ESMA. Esta sorpresiva decisión causó enorme irritación en múltiples sectores, particularmente en las asociaciones de derechos humanos, en tanto este edificio fue siempre el símbolo de la injusticia y las violaciones a los derechos. Si bien nunca logró cumplir con su deseo de borrar la memoria histórica de los argentinos, sus acciones profundizaron el descontento y la conflictividad de la memoria del pasado reciente.

La década de los noventa fue un período particularmente funesto para la lucha por la memoria, la justicia y los derechos humanos, que se vio agravada por las acciones de Menem en defensa de los militares que lideraron la dictadura más cruenta del país.

\subsection{La inestabilidad institucional. Presidencia de Fernando de la Rúa (1999-2001)}

En 1997, con el aporte de varios partidos opositores, y encabezada por la UCR y el Frente País Solidario (FrePaSo), se constituye la Alianza por el Trabajo, la Justicia y la Educación, más conocida simplemente como La Alianza, conducida por Fernando de la Rúa. Esta agrupación se impuso con un $48.37 \%$ de los votos. Más allá de las virtudes que podrían demostrar los candidatos electos, el resultado de la elección constituía un clamor muy intenso del pueblo argentino, que demandaba un cambio en los rumbos políticos. A mediados del año 2000, el país entró en una situación de ingobernabilidad de repercusiones internacionales, la crisis social recrudeció, comenzaron a sucederse una serie de actos de vandalismo, saqueos, protestas y huelgas en todo el país. La crisis llegó a su punto de mayor expresión el 19 de diciembre de 2001, cuando de la Rúa, en su falta de capacidad evidente, decretó el estado de sitio (Galafassi). De la Rúa debió renunciar, y dejó el cargo cuando Argentina se encontraba sumida en una crisis que no aparentaba dar salidas, al menos a corto plazo. 
El papel del Estado en la construcción de la memoria

Siguiendo con la inercia que se había establecido en la presidencia de Menem, los reclamos respecto de los organismos de derechos humanos quedaron nuevamente relegados a un plano que no gozaba de mayor prominencia.

Tras la renuncia de de la Rúa, el país entró en una situación de acefalía. Los argentinos reafirmaron su decisión de continuidad en los valores democráticos, y el intenso debate sociopolítico que primó daba por sentado que, sin lugar a dudas:,no importaba el costo, Argentina no volvería a someterse a un gobierno militar.

Los argentinos se encontraron entonces ante una profunda crisis institucional y ante un grave debate, en el que habrían de decidir el tipo de país que deseaban. Esto implicó una reflexión más concienzuda, que limitó algunas expresiones exageradas producidas por la desesperación. El retorno de los intereses ciudadanos hacia temas relacionados con las deudas pendientes de los gobiernos con las víctimas de la dictadura militar y la necesidad de esclarecer el pasado y distribuir justicia se impuso en la agenda nuevamente.

Luego de una sucesión de cinco efímeras presidencias, el llamado a elecciones de abril de 2003 materializó el deseo de la gran mayoría de los argentinos de restablecer el rumbo democrático elegido. Néstor Kirchner encabezó una de las listas de su partido. Con su ingreso al poder, la Argentina emprendió el inicio de una nueva etapa, que representaría aires nuevos y un espacio fértil para saldar las cuentas de los sucesivos gobiernos democráticos con las asociaciones de derechos humanos y con toda la ciudadanía.

\subsection{La presidencia de Néstor Kirchner (2003-2007)}

El triunfo de Kirchner puso fin a las traumáticas luchas sucesorias. Su perfil de socialdemócrata lo diferenciaba de los demás candidatos y, a pesar de no ser demasiado conocido en el contexto nacional, su imagen fue creciendo gradualmente durante la campaña, que fue conducida por su esposa, Cristina Fernández, hasta obtener un $22 \%$ de los votos.

Muchos son los aspectos de la presidencia de Kirchner que resultan dignos de ser destacados, tanto positivos como negativos (véase, por ejemplo, Svampa, Simonof; Cheresky; Cherney et al., Borón). Sin embargo, su accionar en el área de 
derechos humanos signó su mandato, tanto por las acciones legales que encabezó como por la firme decisión de reestablecer un consenso con la historia.

A inicios de 2003, un grupo de diputados del partido Izquierda Unida presentó en el Parlamento un proyecto para anular las tan conflictivas "Leyes del Olvido", o "Leyes de la Impunidad". El proyecto fue debatido intensamente y aprobado en agosto de 2003, por lo cual la Cámara Federal de la ciudad de Buenos Aires ordenó la reapertura de dos causas, que involucraban a alrededor de 700 militares, con el propósito de investigar los hechos ocurridos en la ESMA y el Primer Cuerpo del Ejército durante la dictadura. Desde entonces, cientos de represores civiles y militares cuyos procesos habían sido interrumpidos en 1986 han sido juzgados y sentenciados.

La sanción de esta ley se presentó en línea con una serie de acciones que evidenciaron la clara intención del presidente Kirchner de hacer que la cuestión de los derechos humanos constituyera un eje central de su presidencia.

Más allá de fuertes críticas que éstas y muchas otras acciones le valieron, fundamentadas en una sobreexplotación de la temática con fines populistas, propósitos de enmascaramiento de otros conflictos, irregularidades en la asignación de fondos a organizaciones, presunto tráfico de influencias, entre muchos otros, el aporte de Kirchner a las causas por la búsqueda de la verdad y la justicia es incuestionable. De todas las acciones que tomó en su defensa, la de mayor repercusión y carácter simbólico fue, sin lugar a dudas, la inauguración del Museo de la Memoria.

\section{La ESMA y el Museo de la Memoria}

El 24 de marzo del 2004, en ocasión del 28 aniversario del golpe militar, Kirchner anunció la creación del Museo de la Memoria en uno de los centros de detención clandestino más emblemático de la última dictadura militar, la Escuela de Mecánica de la Armada, esma. Así, reavivó el debate sobre la memoria, la justicia y la necesidad de que la sociedad hiciera las paces con su pasado traumático (Fernández Peychaux).

La ESMA comprende un predio de 17 hectáreas ubicado en la capital de Argentina, a pocos metros del Río de la Plata. Algunos autores, como Daleo, la han 
El papel del Estado en la construcción de la memoria

considerado "una unidad productiva del terror" (237), ya que por sus instalaciones se estima que pasaron más de 5 mil prisioneros, de los cuales la mayoría están desaparecidos. Funcionó además como centro estratégico y de operaciones de las Fuerzas Armadas, y de sus parques partían los "vuelos de la muerte", helicópteros con prisioneros que luego de ser sedados eran arrojados vivos al mar como forma sistemática de exterminio. Contaba con una sala en la que las embarazadas detenidas daban a luz a sus hijos, la mayoría de los cuales eran sustraídos para el inicio de los procesos de tráfico de bebés, práctica frecuente en la época y que hasta el día de hoy repercute en búsquedas incansables de nietos de desaparecidos.

La gran relevancia social e histórica de la inauguración del Museo de la Memoria radica en la posibilidad de obtener verdad y justicia para las víctimas y sus familiares, y de descubrir finalmente la veracidad sobre lo sucedido durante el terrorismo de Estado. Esta acción de Kirchner representa la voluntad general, en cuyo interés se compromete no solamente el gobierno sino también toda la sociedad. Si bien los actos conmemorativos de esta naturaleza pueden ser considerados como rituales vacíos, su valor reside en su carácter simbólico instrumental, ya que posibilitan la presentación de los partidos gobernantes y de sus ideologías, así como también la determinación política de la sociedad de instalar un suceso histórico en un plano de trascendencia, "alejado de narrativas que se asocian a fines políticos oportunistas" (Wodak y Auer 19).

Además de la relevancia histórica, ideológica y simbólica de la inauguración del Museo de la Memoria, el discurso que en esa ocasión pronunció el presidente Kirchner fue categórico, terminante e inescrutable. Los medios lo construyeron como un discurso desde la autoridad plena del ejercicio de su función, pero contrastado con una actitud de profunda sumisión a la sociedad. En él asumió, en su carácter de mandatario, responsabilidad absoluta por las injusticias cometidas por los presidentes democráticos que lo habían precedido por no contribuir a la causa de la construcción activa de la memoria. Expresó su vergüenza como argentino y pidió perdón a las víctimas, a sus familiares y a toda la sociedad por las atrocidades cometidas.

El impacto emocional que generó en todas las audiencias fue enorme. Así lo construyeron los medios, que jugaron un papel fundamental. El discurso fue reproducido casi literalmente en la mayoría de los medios nacionales y tuvo grandes repercusiones en el extranjero también. Así se marcaba el final de un capítulo 
doloroso en la historia de la Argentina, y el inicio de una nueva etapa de configuración social que ya se encontraba en condiciones de avanzar sobre una base de reconciliación con su pasado. Si bien resulta posible que la resolución final no se encuentre nunca y, efectivamente, no se ha encontrado aún, este evento marcó un hito en la dinámica de la construcción de la memoria argentina. Los textos que analizamos en este trabajo corresponden a las repercusiones mediáticas de este hecho histórico para la construcción de la memoria argentina.

\section{Metodología}

\subsection{Corpus: textos analizados}

El análisis implementado es de carácter eminentemente cualitativo (Guba y Lincoln), pero auxiliado con herramientas digitales básicas de descripción textual (AntConc $3 \cdot 4 \cdot 4 \mathrm{~W})$. Analizamos un corpus que consideró cinco textos, todos publicados el mismo día, 24 de marzo de 2004, jornada posterior a la inauguración del Museo de la Memoria. Los artículos seleccionados corresponden a los cinco diarios de mayor tirada en su región. La Tabla 1 presenta la composición y caracterización de los textos analizados, que en su totalidad comprendieron 2611 palabras.

\begin{tabular}{l|l|l|l} 
Diario & $\begin{array}{l}\text { Lugar de } \\
\text { publicación }\end{array}$ & Titular de la noticia & $\begin{array}{l}\text { N. }{ }^{\text {de }} \\
\text { palabras }\end{array}$ \\
\hline El Tribuno & Salta & $\begin{array}{l}\text { La ESMA pasó de ser un centro de torturas a Museo } \\
\text { de la Memoria }\end{array}$ & 570 \\
\hline Los Andes & Mendoza & EsMA: Kirchner pidió perdón en nombre del Estado & 687 \\
\hline La Capital & Rosario & $\begin{array}{l}\text { Kirchner inauguró el Museo de la Memoria y pidió } \\
\text { "perdón" en nombre del Estado }\end{array}$ & 373 \\
\hline La Nación & Buenos Aires & "Vengo a pedir perdón por el Estado Nacional" & 729 \\
\hline $\begin{array}{l}\text { La Voz del } \\
\text { Interior }\end{array}$ & Córdoba & Durísima respuesta de De la Sota a Bonafini & 257
\end{tabular}

Tabla 1. Noticias analizadas y sus características 
En el caso de haber más de una noticia sobre la temática, se privilegió la selección de la noticia local, en virtud de que una exploración preliminar determinó que era el texto con mayor carga evaluativa y, en consecuencia, de mayor riqueza para nuestros propósitos. Debido a restricciones de diverso tipo, no se analizan otros elementos de las noticias, tales como las fotografías o infografías. El estudio incorpora exclusivamente los aspectos verbales.

\subsection{Procedimiento de análisis}

Una vez seleccionados y transcritos los textos se procedió al análisis que se desplegó siguiendo el recorrido que detallamos a continuación: (1) digitalización del corpus, (2) análisis de frecuencias lexicales (auxiliado digitalmente con el software AntConc versión 3.4.4w), (3) agrupamiento de ítems lexicales en categorías emergentes, (4) determinación de los recursos valorativos y (5) interpretación de la relación entre el uso de recursos y el fenómeno social bajo análisis.

Para la determinación de los recursos valorativos utilizamos las categorías del Sistema de Valoración propuesta por Martin y White en el marco de la Lingüística Sistémico Funcional (Halliday). En particular, hacemos referencia a los subsistemas de la actitud, que comprenden la codificación de la actitud, juicio y apreciación en el discurso.

Los actores sociales fueron categorizados siguiendo la propuesta de van Leeuwen. Esta comprende no solamente "actores sociales" en su sentido general, sino cualquier tipo de forma referencial a seres humanos y a su representación discursiva. Esto es de fundamental importancia ya que la selección de forma representacional de los actores y eventos en el discurso construye las posturas ideológicas de quienes producen los textos. 


\section{Resultados del estudio}

A fin de determinar la manera en que los textos analizados contribuyeron a la configuración de la memoria y del papel del Estado en el pasado reciente posdictatorial de la Argentina, primeramente, describimos los recursos léxico-gramaticales empleados, que se presentan en la Tabla 2. Consideramos en este recorte solamente las palabras conocidas en la disciplina como "palabras de contenido" (verbos, adjetivos, sustantivos y adverbios), dejando de lado aquellas que no cumplen un papel semántico discursivo de relevancia. Se incluyen aquellos ítems que se presentaron en los cinco textos analizados.

\begin{tabular}{l|c|c}
\multicolumn{1}{c|}{ PALABRA } & RANGO & FRECUENCIA \\
\hline Kirchner & 16 & 22 \\
\hline ESMA & 18 & 20 \\
\hline Estado & 19 & 20 \\
\hline memoria & 23 & 16 \\
\hline acto & 24 & 15 \\
\hline presidente & 25 & 15 \\
\hline jefe & 30 & 11 \\
\hline nombre & 31 & 11 \\
\hline odio & 38 & 10 \\
\hline justicia & 40 & 9 \\
\hline lugar & 59 & 7 \\
\hline dictadura & 63 & 6 \\
\hline gobernadores & 64 & 6 \\
\hline mandatario & 67 & 6 \\
\hline mayo & 68 & 6 \\
\hline militar & 69 & 6 \\
\hline nación & 70 & 6 \\
\hline paso & 71 & 6 \\
\hline plaza & 72 & 6 \\
\hline
\end{tabular}

\begin{tabular}{c|c|c} 
lucha & 41 & 9 \\
\hline museo & 42 & 9 \\
\hline argentina & 43 & 9 \\
\hline discurso & 48 & 8 \\
\hline guía & 50 & 8 \\
\hline hijos & 51 & 8 \\
\hline impunidad & 52 & 8 \\
\hline perdón & 54 & 8 \\
\hline desaparecidos & 55 & 7 \\
\hline golpe & 57 & 7 \\
\hline Ibarra & 58 & 7 \\
\hline rencor & 74 & 6 \\
\hline argentino & 78 & 5 \\
\hline derechos & 79 & 5 \\
\hline gobierno & 80 & 5 \\
\hline futuro & 81 & 5 \\
\hline humanos & 82 & 5 \\
\hline predio & 86 & 5
\end{tabular}

Tabla 2. Análisis de frecuencia de palabras de contenido (primeras 100 ocurrencias/ identificadas en todos los textos) 
Estos resultados se agruparon por categorías emergentes, combinando en cuatro casos aquellos términos que componían frases indisolubles: derechos humanos, plaza de mayo, golpe militar y en nombre del Estado. Las agrupaciones produjeron 8 categorías, que presentamos en la Tabla 3 a continuación.

\begin{tabular}{|c|c|c|}
\hline Categoría & Elementos identificados & Instancias \\
\hline $\begin{array}{l}\text { Actores sociales construidos } \\
\text { como institución }\end{array}$ & $\begin{array}{l}\text { [en] nombre [del] Estado } \\
\text { (20), presidente (15), jefe (11), } \\
\text { dictadura (6), nación (6), } \\
\text { gobernadores (6), mandatario } \\
\text { (6), gobierno (5), }\end{array}$ & 75 \\
\hline $\begin{array}{l}\text { Actores sociales construidos } \\
\text { como lugares }\end{array}$ & $\begin{array}{l}\text { ESMA (20), museo (9), } \\
\text { Argentina (9), lugar (7), Plaza } \\
\text { [de] Mayo (6), predio (5), } \\
\text { argentinos (5) }\end{array}$ & 61 \\
\hline Actores sociales nominales & Kirchner (22), Ibarra (7), & 29 \\
\hline Eventos sociales & acto (15), discurso (8) & 23 \\
\hline $\begin{array}{l}\text { Actores sociales construidos } \\
\text { como relación }\end{array}$ & hijos (8), desaparecidos (7) & 15 \\
\hline Valores sociales abstractos & $\begin{array}{l}\text { Memoria (16), justicia (9), } \\
\text { perdón (8), impunidad (8), guía } \\
\text { (8), Derechos humanos (5) }\end{array}$ & 54 \\
\hline Etapas del proceso histórico & $\begin{array}{l}\text { lucha (9), golpe militar (7), paso } \\
\text { (6), futuro (5) }\end{array}$ & 27 \\
\hline Afecto & odio (10), rencor (6) & 16 \\
\hline
\end{tabular}

Tabla 3. Categorías, elementos que las componen y cantidad de instancias identificadas

Como puede observarse, 2 de las categorías se vinculan de manera estrecha con el tópico de las noticias: el evento social que se reporta (acto, discurso), y los dos políticos que estaban directamente involucrados en este evento (el presidente de la nación, Kirchner, y el intendente de la Ciudad Autónoma de Buenos Aires, Ibarra). Estas categorías son las ineludibles de cualquier texto de este género. Sin embargo, no son las de mayor incidencia en la semántica de este corpus. Los diarios coinciden en representar la inauguración del Museo de la Memoria como una cuestión primordialmente institucional, como una cuestión de Estado. Esta representación corrobora lo que afirman Wodak y Meyer sobre la responsabilidad de 
los Estados como entes responsables de los hechos sociales traumáticos y en gran medida responsables de la configuración de la memoria colectiva de esos hechos.

El segundo lugar lo ocupa la categoría de actores sociales representados en referencia a determinados lugares. Esta es una categoría muy amplia y podría interpretarse de múltiples maneras. En el contexto de estos discursos, y en este momento sociohistórico en particular, observamos que los actores de esta categoría son de dos subtipos principales: los que referencian al lugar físico, al museo (tales como esMa, museo, lugar, Plaza [de] Mayo, predio), mientras que otro tipo es el constituido por los habitantes de este país, quienes fueron protagonistas de la historia reciente que se está honrando (Argentina y argentinos). La última categoría, y con una frecuencia mucho menor, es la de relacionalizaciones (hijos y desaparecidos), que, sorprendentemente, se encuentra en un lugar muy alejado.

Este análisis nos permite visualizar que los medios no construyeron estos discursos sobre los desaparecidos, los militares, o el golpe. A diferencia de lo que había ocurrido hasta ese momento, el rumbo de la construcción de la memoria, lo que se ha denominado la "dinámica de la memoria" (Pascual, La violación), se construye en los medios como un diálogo entre el Estado y los ciudadanos.

Resulta revelador que al analizar los valores abstractos que se construyen como foco de interés, encontramos una elevada incidencia de entidades como memoria, justicia, perdón, impunidad, guía, derechos humanos. La de mayor frecuencia es la memoria, seguida de la justicia. Estos conceptos se vinculan sistemáticamente a los de perdón, corroborando una vez más el papel nodal que juega el Estado en la conformación de la memoria. En los medios, el Estado se autoconstruye en la voz del mandatario como quien encabeza este proceso de construcción de memoria sobre la base de la justicia que se promueve.

En lo que respecta a la categoría identificada como Etapas del proceso histórico, corroboramos una vez más el carácter dinámico de la conformación de la memoria, con la representación de cuatro entidades: lucha, golpe militar, paso y futuro. Estas elecciones dan una clara cuenta de la dinámica, que va desde el pasado, desde el hecho traumático, el golpe militar, atravesando la historia en esta forma lexicalizada metafóricamente como un paso, y con vistas a un futuro. Resulta interesante que todo este proceso temporal y social se ve marcado por la lucha por mantener la memoria para consolidar un futuro de armonía. 
En lo que respecta a las instancias de valoración, observamos varias instancias que configuran juicio, y que fueron incluidas como actores sociales (tales como perdón, justicia, impunidad). Sin embargo, las dos instancias que se destacan son las de afecto, altamente atípicas en el género discursivo noticia, $y$, tal como era de esperarse, construidas en el discurso por medio de recursos de intertextualidad, en la voz del entonces presidente Kirchner: odio y rencor. Tal como se muestra en el análisis de concordancia de la Figura 1, los términos se utilizan de manera conjunta, y como parte de una conjunción coordinante: ni odio ni rencor. Este uso enfatiza la contraexpectativa que el mandatario intenta consolidar. La memoria argentina ya no debe sustentarse en esas dimensiones del afecto. Su accionar y la memoria deben tender a la justicia y a la lucha contra la impunidad.

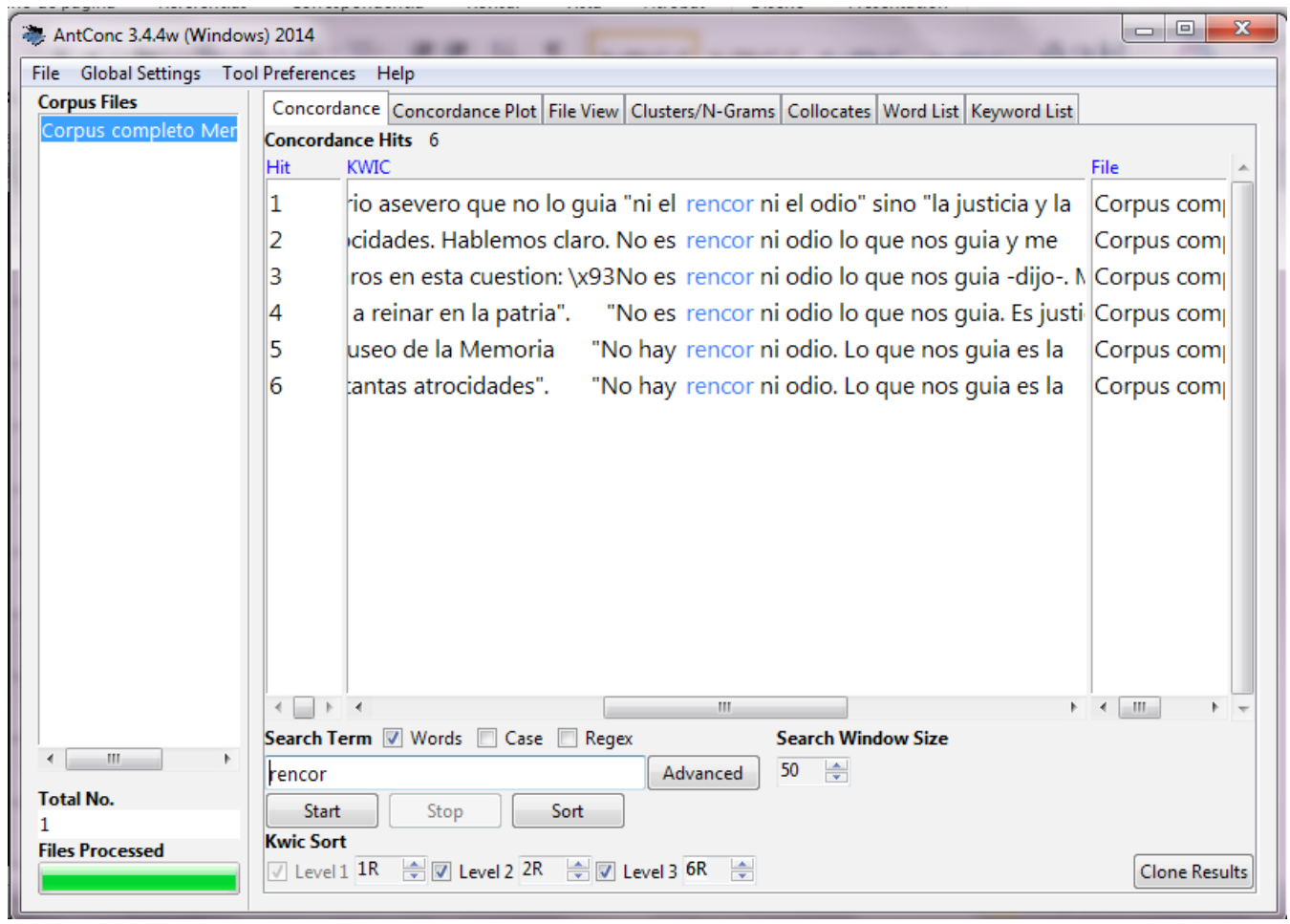

Figura 1. Concordancia de uso del término "rencor" 
Mariana Pascual

Esta noción está atravesada por el concepto fundamental del perdón que constituye el tema central de este discurso, de este evento social que construyen los medios y del tipo de memoria que se codifica, no solamente desde los relatos y las memorias individuales, sino como construcción de valores colectiva que está fundamentalmente moldeada por las acciones de los Estados y sus actitudes ante los pasados traumáticos.

\section{Conclusiones}

En este trabajo nos propusimos indagar acerca de la manera en la que cinco medios argentinos representaron la inauguración del Museo de la Memoria de la Ciudad de Buenos Aires. Planteamos nuestro objetivo de determinar el papel del Estado en la construcción colectiva de la memoria por medio de un análisis léxico-gramatical de elementos valorativos y entidades evaluadas.

Los resultados corroboraron que la construcción de los medios fue de una sociedad que, siguiendo la guía del mandatario en ejercicio, optó por reconocer públicamente las atrocidades cometidas y pedir perdón por tanto dolor causado. En los extremos de la polaridad del afecto negativo encontramos el odio y el rencor, a los que el presidente insta a la ciudadanía a dejar en el pasado. De la misma manera que sucedió en otras sociedades, la inauguración del Museo de la Memoria marcó un punto de quiebre en la configuración de la memoria colectiva del país, determinado de manera fundamental por la actitud del Estado frente a un tema de enorme sensibilidad y conflictividad.

Estos resultados pueden contribuir a la comprensión de un tema de relevancia en la historia reciente y del papel fundamental que los discursos de los medios juegan en su construcción. Así mismo, los aportes nos permiten comprender mejor el papel que el Estado juega en este proceso. Futuros estudios pueden establecer un recorrido cronológico de la dinámica evaluativa de la construcción de la memoria en Argentina. Así mismo, investigaciones comparativas que consideren lo acaecido en otras sociedades pueden resultar de gran utilidad para la comprensión de este fenómeno tan profundamente humano y desafiante. 


\section{Mariana Pascual}

Doctora en Lingüística UbA, Magíster en Inglés, Lingüística Aplicada. Profesora Asociada de la carrera de Letras Hispánicas de la Pontificia Universidad Católica de Chile con amplia trayectoria en análisis (crítico) del discurso. Sus áreas de interés son el discurso de los medios, en particular en temáticas relativas a derechos humanos y construcción de memoria colectiva. Ha desarrollado análisis de la construcción de la memoria y de la dinámica evaluativa en análisis diacrónicos y sincrónicos de discursos de medios gráficos de la Argentina posdictatorial. Estudia, así mismo, la comunicación en contextos de salud y ciencia. En sus trabajos indaga primordialmente el uso de los recursos de construcción discursiva de la evaluación, la postura interpersonal e ideológica.

\section{Obras citadas}

Achugar, M. Construcción de la memoria: Análisis de la confesión de un represor. Discurso y Sociedad, 4.1 (1999): 7-34.

Achugar, M. "What we remember: The construction of memory in military discourse", Discourse Approaches to Politics, Society and Culture Series. Eds. Ruth Wodak and Greg Myers. University of Lancaster: John Benjamins Publishing Company, 2008. Impreso.

Achugar, M., A. Fernández, y Morales, N. "(Re) presentando el pasado reciente: la última dictadura uruguaya en los manuales de historia”. Discurso \& Sociedad 5.2 (2011): 196-229.

Assmann, A. Commemorative spaces: Forms and changes in cultural memory. 4th edition. Munich: C.H.Beck, 2009. Impreso.

Assmann, A. From collective violence to a common future: Four models for dealing with a traumatic past. Memory and Justice. eds. Wodak, R. y Auer. Vienna: Passagen Verlag. 2009. 31-48. Impreso. 
Mariana Pascual

Benítez, D. H. y Mónaco, C. “La dictadura militar, 1976-1983”. Comps. Kessler, G.y Luzzi, M. Problemas socioeconómicos contemporáneos. Los Polvorines: Universidad Nacional de General Sarmiento, 2007. Web. <http://www.riehr.com. ar/archivos/Educacion/La\%2odictadura\%2omilitar\%20моnaco\%2oвenitez.pdf>

Borón, A. "Reflexiones en torno al gobierno de Néstor Kirchner". Revista SAAP 2.1 (2004): 187-205. Impreso.

Crenzel, E. La historia política del Nunca Más. La memoria de las desapariciones en Argentina. Siglo xxi Editores: Buenos Aires, 2008. Impreso.

Cheresky, I. “Argentina: cambio de rumbo y recomposición política”. Nueva Sociedad 193 (2004): 4-16.

Cherney, N., Feierherd, G., \& Novaro, M. "El presidencialismo argentino: de la crisis a la recomposición del poder (2003-2007)”. América Latina hoy 54 (2010): 15-41.

Daleo, G. El movimiento popular y la lucha contra la impunidad en la Argentina. Miscellánia, 2007. Web. http://seneca.uab.es/hmic

Dussel, I., Finocchio, S. y Gojman, S. Haciendo memoria en el país del Nunca Más. (Nueva edición). Buenos Aires: Eudeba, 2003. Impreso.

Fernández Peychaux, M. I. "Política y justicia en la memoria histórica argentina”. Congreso Internacional 1810-2010: 200 años de Iberoamérica, 2010. 1693-1715. Impreso.

Finocchio, S. Entradas educativas en los lugares de la memoria. En M. Franco, y F. Levin comps. Historia reciente. Perspectivas y desafíos para un campo en construcción. Paidós: Buenos Aires, 2007. 253-279. Impreso.

Galafassi, G. P. "Sucesos Argentinos: breve relato del proceso capitalista neoliberal y su crisis, y del surgimiento de una incipiente rebelión popular". Theomai 5 (2002). Impreso.

Guba, E. G., y Lincoln, Y. S. “Competing paradigms in qualitative research”. Eds. Denzin, N.K. y Y.S. Lincoln. Handbook of qualitative research. California: Sage, 1994. Impreso.

Halliday, M. A. K. Language as a Social Semiotic. London: Edward Arnold, 1978. Impreso. 
El papel del Estado en la construcción de la memoria

Koselleck, R. Futuro pasado. Para una semántica de los tiempos históricos. 1979. Barcelona: Paidós, 1993. Impreso.

Lavandera, B. R. Intertextual relationships: Missing people in Argentina. Washington: Georgetown University Press, 1986. 121-139. Impreso.

Martin, J. R., y White, P. R. R. The Language of Evaluation: Appraisal in English. London: Palgrave; New York: Macmillan, 2005. Impreso.

O’Donnell, G. (1997). Contrapuntos. Ensayos escogidos sobre autoritarismo y democratización. Buenos Aires: Paidós. Impreso.

Oteíza, T. "How Contemporary History is Presented in Chilean Middle School Textbooks". Discourse \& Society 14.5 (2003): 639-660.

Oteíza, T. y Pinto D. "Agency, Responsibility and Silence in the Construction of Contemporary History in Chile and Spain”. Discourse \& Society 19.3 (2008).

Pascual, M. "Coming to terms with a traumatic past: Social actors in the Argentine media”. New trends and methodologies in applied English language research III. Synchronic and diachronic studies on discourse, lexis and grammar processing. Eds Bemposta-Rivas S., Bouzada-Jabois C., Fernández-Pena Y., Bouso T., CalvoBenzies, Y.J. \& Tamaredo-Meira I. Peter Lang. Linguistic Insights Series, 2017. Impreso.

Pascual, M. La violación a los derechos humanos en la Argentina: dinámica evaluativa de dos décadas de representación en medios. Discurso \& Sociedad 11.3 (2017): 388-413.

Pascual, M. 2014. "La asociación de recursos de valoración: el caso de las organizaciones de derechos humanos en la prensa escrita argentina”. Revista Onomázein 1.29 (2014).

Simonoff, A. "Regularidades de la Política Exterior de Néstor Kirchner". Cofines de relaciones internacionales y ciencia política 5.10 (2009): 71-86.

Svampa, M. "Argentina: una cartografía de las resistencias (2003-2008). Entre las luchas por la inclusion y las discusiones sobre el modelo de desarrollo". Observatorio Social de América Latina (OSAL) 9.24 (2008). 
van Leeuwen, T. "The representation of social actors". Texts and Practices: Readings in Critical Discourse Analysis. Eds. C.R. Caldas Coulthard, y M. Coulthard. London: Routledge, 1996. Impreso.

van Leeuwen, T. Discourse and practice: New tools for critical discourse analysis. Oxford: Oxford University Press, 2008. Impreso.

Vitale, M.A. "Memoria y acontecimiento. La prensa escrita argentina ante el golpe militar de 1976". Los Estudios del Discurso: nuevos aportes desde la investigación en la Argentina. Coord. P. Vallejos. Bahía Blanca: Editorial de la Universidad Nacional del Sur, 2007. 165-182. Impreso.

Wodak, R. “The discourse-historical approach". R. Wodak y M. Meyer eds. Methods of critical discourse analysis. London: Sage, 2001. 63-95. Impreso.

Wodak, R. y Auer, G. eds. Memory and justice: Confronting traumatic pasts. Vienna: Passagen Verlag, 2009. Impreso.

Wodak, R. y Meyer, M. Methods of Critical Discourse Analysis. London: Sage, 2008. Impreso.

Zullo, J. "Enseñar el Golpe: enunciadores, participantes y acontecimientos construidos para el aula". Raiter y Zullo coords. Esclavos de las palabras. Buenos Aires: Editorial de la Facultad de Filosofía y Letras UBA, 2012. Impreso. 